\title{
ROLE OF COMBINATION DRUG THERAPY FOR MANAGEMENT OF HYPERTENSION WITH INCREASING AGE
}

\author{
PARTAP BIR SINGH, SUKHRAJ SINGH, GURPREET KAUR GILL* \\ Department of Medical Laboratory Technology, Khalsa College of Pharmacy and Technology, Amritsar, Punjab, India. \\ Email: gurpreet_pau25@yahoo.com
}

Received: 05 June 2021, Revised and Accepted: 16 September 2021

\section{ABSTRACT}

Objective: In South Asia, hypertension is the third highest factor contributing in public health burden of disease and major risk factor for coronary artery disease especially in women and old age people. The study was aimed to determine the role of gender and age (20-80 years) on severity of hypertension to design an effective schedule for management of hypertension.

Methods: The levels of serum cholesterol, triglycerides (TG), high-density lipoprotein (HDL), low-density lipoproteins (LDL), and blood pressure (BP) of 240 hypertensive patients were monitored. Cholesterol, TG, and HDL levels were detected using ERBA Reagent kit of Transasia Bio-medicals LTD by CHOD-PAP, glycerol phosphate oxidase trinder End point, and polyvinyl sulfonic and polyethyleneglycol-methyl ether based methods, respectively.

Results: The BP and levels of serum cholesterol, TG and LDL were increased in both the genders after 40 years of age. However, the rise in levels of these parameters was more in females in comparison to males. A hypertension management schedule involving (BP)/Cholesterol lowering drugs and lifestyle changes for period of 60 days showed that combination drug therapy was more effective than monotherapies of same drugs used at higher dosages.

Conclusion: Hypertensive patients strictly followed the prescribed healthy food and exercise schedule showed improvement in their BP and lipid profile even with limited drug intervention.

Keywords: Hypertension, Low-density lipoprotein, Triglycerides, Cholesterol and blood pressure.

(C) 2021 The Authors. Published by Innovare Academic Sciences Pvt Ltd. This is an open access article under the CC BY license (http://creativecommons.org/ licenses/by/4.0/) DOI: http://dx.doi.org/10.22159/ajpcr.2021v14i10.42431. Journal homepage: https://innovareacademics.in/journals/index.php/ajpcr

\section{INTRODUCTION}

Hypertension majorly poses a public health burden of disease in South Asia [1,2]. It is responsible for $57 \%$ of all stroke deaths and $24 \%$ of all coronary heart disease (CHD) deaths in India [3]. In comparison to the year 2000, the number of adults with hypertension is predicted to increase by $\sim 60 \%$ to a total of 1.56 billion by the year 2025 worldwide due to sedentary life style and unconventional food habits whereas uncontrolled hypertension may ultimately lead to organs damage. Hence, uncontrolled hypertension is the major risk factor for coronary artery disease and stroke. The WHO rated hypertension as one of the most important causes of premature death worldwide [4]. However, only about $25.6 \%$ of treated patients have awareness regarding treatment and control of blood pressure (BP) in multicenter study from India [5].

According to the worldwide data, around $20.6 \%$ of Indian men and $20.9 \%$ of Indian women were suffering from hypertension in 2005 which is projected to go up to 22.9 and 23.6 for Indian men and women, respectively [6]. Recent studies from India have shown the prevalence of hypertension to be $25 \%$ in urban and $10 \%$ in rural people in India [7]. The risk of developing essential hypertension increases with age. The older persons are more likely to get high BP. Men are more likely to have high BP than women up to age the of 45 , and by the age of 65 it's more common in women which may include environmental and hormonal factors [5].

Antihypertensive drug therapy is used to control the hypertension. Most of these drugs are mainly designed based on the understanding of renin-angiotensin aldosterone system. Renin a serine protease protein and enzyme secreted by the kidneys that regulate the blood volume and arterial vasoconstriction thus, regulates the arterial BP. Renin enzyme circulates in the blood and hydrolyzes angiotensinogen (a peptide hormone and secreted from the liver) to Angiotensin-I which is further cleaved in the lungs by endothelial-bound angiotensin-converting enzyme into angiotensin II which is the potent constrictor of all blood vessels causing the BP to rise. Angiotensin II also acts on the adrenal glands and releases aldosterone, which increase re-absorption of sodium and water, leading to raised blood volume and raised BP.

Hence, we studied the level of hypertension in males and females of different age groups, evaluated the major factors responsible for hypertension and effective therapy for its control.

\section{MATERIALS AND METHODS}

The blood samples of 240 patients suffering from hypertension/ hypertension related factors of different age groups of male/females were collected from Sharma clinical laboratories and Khalsa diagnostic laboratory of Amritsar, Punjab, India. The study was conducted on already available biological material obtained from the diagnostic laboratories with the written consent from the patients which is ethically approved. The study protocol was approved by institutional ethics committee.

The data collection questionnaire was well prepared and all variables were filled on the data extraction format daily which included name, age, height, weight, dietary habits, daily routine, family history, and health problems such as cardiovascular diseases and hypertension was recorded. The blood/serum of these patients was tested for level of cholesterol, triglycerides (TG), high-density lipoprotein (HDL), and low-density lipoprotein (LDL) to find their correlation with hypertension among different age groups in males and females. The BP of each patient was measured 2 times on the right arm using automatic electronic device (OMRON HEM-7261). The average of two readings was used. 
The detection of cholesterol, TG, HDL, and LDL in serum samples was done using kits obtained from Beacon Diagnostics Pvt. Ltd., Navsari, Gujrat, India and Trans Asia (ERBA) Bio-Medicals Ltd Mumbai, India. All the tests were standardized and automated.

\section{Estimation of cholesterol level in serum}

The cholesterol from the blood serum was detected by CHOD-PAP Method using Erba Cholesterol Diagnostic Test Kit based method (Transasia Bio-medicals LTD) in which $1 \mathrm{ml}$ of reagent was added to $10 \mathrm{ml}$ of the prepared serum and solution was allowed to mix well and incubated at $37^{\circ} \mathrm{C}$ for $5 \mathrm{~min}$. Cholesterol esterase hydrolyses esterifies cholesterols to free cholesterol which is oxidized to form hydrogen peroxide which further reacts with phenol and 4-amino antipyrine form a red colored quinoneimine dye complex measured against Blank at $505 \mathrm{~nm}$ which is directly proportional to the amount of cholesterol present in the sample. The level of cholesterol was estimated in $\mathrm{mg} / \mathrm{dl}$ by using formulae Abs. T/Abs. $\mathrm{S} \times 200$, where $\mathrm{T}$ is test sample, Abs is absorbance, and $\mathrm{S}$ is sample.

\section{Estimation of TG, HDL, and LDL level in serum}

The TG from the blood serum was detected using kit-based method (ERBA TG Biochemistry Reagent kit, Transasia Bio-medicals LTD) using glycerol phosphate oxidase (GPO) trinder End point method in which $1 \mathrm{ml}$ of reagent was added to $10 \mathrm{ml}$ of the prepared serum allowed to mix well and incubated at $37^{\circ} \mathrm{C}$ for $5 \mathrm{~min}$. The level of triglyceride was detected based on the hydrolysis of TG to glycerol and free fatty acids. The glycerol is phosphorylated to glycerol-3-phosphate which is then oxidized by GPO to yield hydrogen peroxide. The hydrogen peroxide causes oxidative coupling of 4-chlorophenol and 4- aminoantipyrine present in the reagents of the kit producing a red colored quinoneimine dye complex detected at $500 \mathrm{~nm}$ which is directly proportional to the concentration of TG in the sample. The level of TG was estimated in $\mathrm{mg} / \mathrm{dl}$ in serum by using formulae, $\mathrm{TG}(\mathrm{mg} / \mathrm{dl})=\mathrm{Abs}$. $\mathrm{T} / \mathrm{Abs} . \mathrm{S} \times 200$.

The estimation of HDL using ERBA HDL direct Reagent kit (Transasia Bio-medicals LTD) by modified polyvinyl sulfonic acid and polyethyleneglycol-methyl ether based method from the blood was detected in which serum $(1000 \mu \mathrm{l})$ was precipitated using $500 \mu \mathrm{l}$ of precipitating reagent in test tube, mixed well and allowed the reaction mixture to stand for $10 \mathrm{~min}$ at room temperature. It was centrifuged at $4000 \mathrm{RPM}$ for $10 \mathrm{~min}$ to obtain a clear supernatant. The $50 \mu \mathrm{l}$ of supernatant, blank, and standard was mixed with $1 \mathrm{ml}$ cholesterol working reagent and incubate at $37^{\circ} \mathrm{C}$ for $10 \mathrm{~min}$. The absorbance of these was measured against reagent Blank at $505 \mathrm{~nm}$ and HDL was calculated as (Abs. of Test/Abs. of Calibrator) $\times$ Concentration of Standard (25) $\times$ Dilution Factor. Based on this, LDL was calculated as per following formula LDL (mg/dl) = Total Cholesterol - HDL $-(\mathrm{TG} / 5)$

\section{Recovery of patients after drug therapy and change in lifestyle}

Eleven patients were selected based upon their high levels of cholesterol and TG in their serum. They were orally administrated to drugs such as Amlodipine, Atenolol, Telmisartan, Atorvastatin, and Ecosprin for 2 months as prescribed by their physicians.

In addition, based on the health conditions few changes were planned in their lifestyle such as incorporation of light exercise/brisk walking and change diet plan inclusion of more fruits, vegetables, whole grains, fish, nuts, poultry, low-fat dairy products, oils with omega 3 fatty acids and, avoiding sugar-containing beverages, red meat, and sweets. The cholesterol, TG and LDL were tested in the serum after two months of drug therapy/change in lifestyle of these selected patients to detect any improvement in their overall health.

\section{RESULTS AND DISCUSSION}

The 240 study subjects of different age groups (20-40, 41-60, and 61-80 years) with 80 patients in each age group were tested for level of cholesterol, TG, HDL, and LDL in their blood/serum to find their correlation with hypertension in both males and females (Tables 1 and 2). Among these 240 patients, the number of males and females was 120 each.

In Tables 1 and 2, it was observed that the rise in levels of serum cholesterol, TG, LDL, and systolic/diastolic BP was more in case of females as compared to males. This unfavorable lipid profile and increase in BP must be due to decrease in level of estrogen in postmenopausal women and lack of workout and imbalanced diet culture as observed in Indian women. Further, with increasing age the levels of these parameters exceed the normal range in case of both males and females due to atherosclerosis and lack of physical activity which is commonly observed in aged persons.

The changes in individual parameter with age of both males and females were observed as under:

Table 1: Mean cholesterol, TG, LDL, and systolic/diastolic BP profile of patients (males and females) of different age groups

\begin{tabular}{lllllll}
\hline $\begin{array}{l}\text { Age } \\
\text { groups (years) }\end{array}$ & $\begin{array}{l}\text { Number of } \\
\text { patients (n) }\end{array}$ & Gender (M/F) & $\begin{array}{l}\text { Cholesterol } \\
\text { (mg/dL) Mean } \pm \text { SD }\end{array}$ & $\begin{array}{l}\text { TG (mg/dL) } \\
\text { Mean } \pm \text { SD }\end{array}$ & $\begin{array}{l}\text { LDL (mg/dL) } \\
\text { Mean } \pm \text { SD }\end{array}$ & $\begin{array}{l}\text { Systolic/Diastolic } \\
\text { BP (mmHg) Mean } \pm \text { SD }\end{array}$ \\
\hline $20-40$ & 48 & M & $195 \pm 8.9$ & $148 \pm 7.6$ & $118 \pm 8.1$ & $139 / 85 \pm 7.3$ \\
& 32 & F & $175 \pm 7.6$ & $129 \pm 9.3$ & $102 \pm 7.8$ & $128 / 80 \pm 8.4$ \\
$41-60$ & 35 & M & $220 \pm 7.3$ & $158 \pm 11.1$ & $143 \pm 7.3$ & $152 / 90 \pm 11.3$ \\
& 45 & F & $197 \pm 6.9$ & $146 \pm 9.3$ & $131 \pm 9.3$ & $146 / 85 \pm 7.9$ \\
$61-80$ & 36 & M & $241 \pm 5.9$ & $162 \pm 9.1$ & $152 \pm 8.2$ & $159 / 90 \pm 9.3$ \\
& 44 & F & $267 \pm 7.8$ & $178 \pm 8.3$ & $169 \pm 7.8$ & $164 / 95 \pm 8.6$ \\
& Total=240 & - & Normal value $\leq 200$ & Normal value $\leq 150$ & Normal value 100-129 & Normal value 120/80 \\
\hline
\end{tabular}

TG: Triglycerides, LDL: Low-density lipoprotein, BP: Blood pressure

Table 2: Percentage of patients of different age groups with high levels of serum cholesterol, TG, LDL and systolic BP

\begin{tabular}{|c|c|c|c|c|c|c|c|c|c|}
\hline \multirow{3}{*}{$\begin{array}{l}\text { Age } \\
\text { groups (years) }\end{array}$} & \multirow[t]{3}{*}{ Gender (M/F) } & \multicolumn{8}{|c|}{ Percentage $(\%)$ of patients } \\
\hline & & \multicolumn{2}{|c|}{$\begin{array}{l}\text { Cholesterol } \\
\text { (mg/dL) range }\end{array}$} & \multicolumn{2}{|c|}{ TG (mg/dL) range } & \multicolumn{2}{|c|}{ LDL (mg/dL) range } & \multicolumn{2}{|c|}{$\begin{array}{l}\text { Systolic/diastolic BP (mmHg) } \\
\text { range }\end{array}$} \\
\hline & & 200-299 & $\geq 300$ & 150-199 & $\geq 200$ & $100-150$ & $\geq 150$ & $120-150 / 70-90$ & $\geq 150 / 90$ \\
\hline \multirow[t]{2}{*}{$20-40$} & $M$ & $15 \%$ & $5 \%$ & $17 \%$ & $10 \%$ & $25 \%$ & $10 \%$ & $52 \%$ & $5 \%$ \\
\hline & $\mathrm{F}$ & 10 & 4 & 13 & 1 & 20 & 6 & 38 & 0 \\
\hline \multirow[t]{2}{*}{$41-60$} & M & 32 & 6 & 19 & 4 & 28 & 12 & 36 & 20 \\
\hline & $\mathrm{F}$ & 28 & 4 & 16 & 6 & 32 & 13 & 29 & 15 \\
\hline \multirow[t]{2}{*}{$61-80$} & M & 23 & 10 & 22 & 13 & 29 & 15 & 19 & 22 \\
\hline & $\mathrm{F}$ & 32 & 15 & 38 & 17 & 33 & 18 & 28 & 31 \\
\hline
\end{tabular}

TG: Triglycerides, LDL: Low-density lipoprotein, BP: Blood pressure 


\section{Cholesterol level test}

It was observed that out of 240 patients the level of cholesterol in 96 patients was either below or near the borderline, that is, $200 \mathrm{mg} / \mathrm{dL}$ but their BP (systolic and diastolic) was found slightly higher, that is, 130/85 than the normal range of 120/80 (Fig. 1). Among these 96 subjects, majority ( 56 subjects) were belonging to the low age group, that is, 20-40 years. Further, as the level of mean cholesterol level in patients increased to the ranges of 200-250, 250-300, and $>300 \mathrm{mg} / \mathrm{dL}$ their BP also increased drastically to 145/95, 160/110, and 195/120, respectively (Fig. 1).

The assessment of data as per the age groups reveals that among 80 patients of age group 20-40 years, 70\% subjects were having leve of cholesterol $<200 \mathrm{mg} / \mathrm{dL}, 25 \%$ having cholesterol in the range of 200-299 mg/dL, and only 5\% with level > $300 \mathrm{mg} / \mathrm{dL}$.

However, in case of next 80 patients with age group range of 41-60 years, $30 \%$ patient showed level of cholesterol $<200 \mathrm{mg} / \mathrm{dL}, 60 \%$ patients were having cholesterol in the range of $200-299 \mathrm{mg} / \mathrm{dL}$, and $10 \%$ with level $>300 \mathrm{mg} / \mathrm{dL}$

Further, among 80 patients in the age group of $61-80$ years $20 \%$ patients showed level of cholesterol $<200-250 \mathrm{mg} / \mathrm{dL}$ whereas $55 \%$ were having cholesterol in the range of 200-299 mg/dL and around $25 \%$ with level $>300 \mathrm{mg} / \mathrm{dL}$ (Fig. 2).

The discussion of cholesterol level in relation to age is important as aging-induces changes in cholesterol metabolism [6]. The reports in literature show that due to low physical activity there is an increase

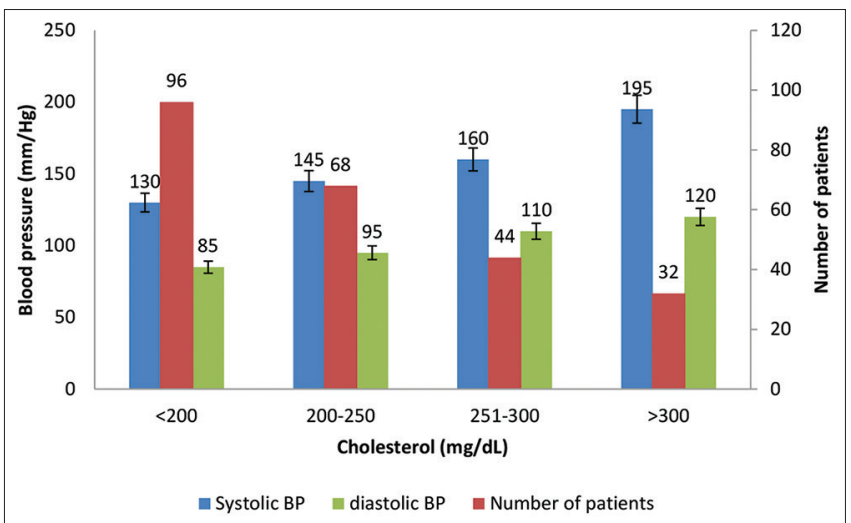

Fig. 1: Describing the relation between levels of serum cholesterol ( $\mathrm{mg} / \mathrm{dL}$ ) and systolic/diastolic blood pressure $(\mathrm{mmHg})$ of 240 patients

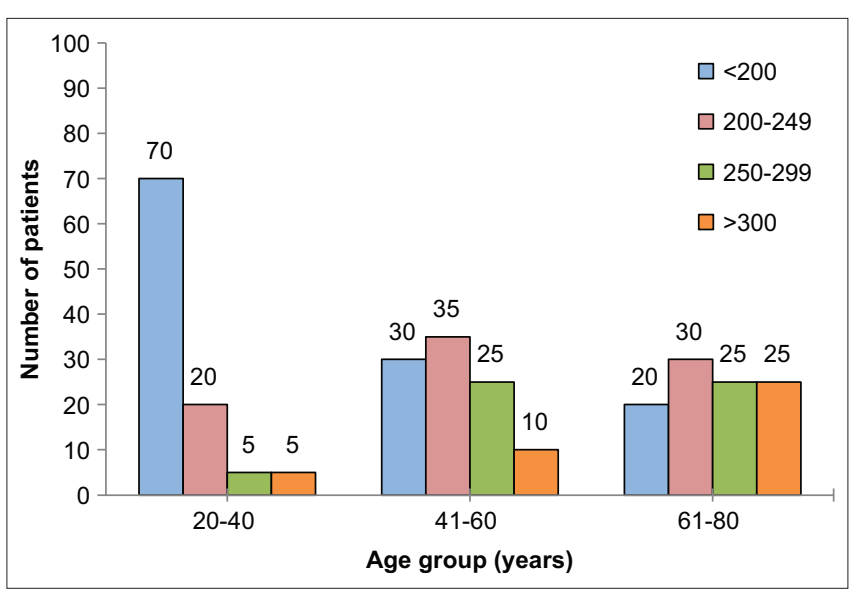

Fig. 2: Describing the levels of serum cholesterol (mg/dL) in patients in adipose tissues, and insulin resistance which leads to increased BP $[7,8]$. The specific reason behind rise in serum cholesterol with increasing age is decrease in breakdown of cholesterol to bile acids due to decreased secretion of growth hormone [9]. The gender related analysis of this study showed that between the ages of 20-40 years, males have significantly higher cholesterol level than females but after the age of 40 years the cholesterol level started increasing in women and it surpassed the cholesterol levels of males after the age of 60 years (Fig, 2). The difference might be caused by deficiency of estrogen levels in postmenopausal women which is mainly associated with an unfavorable lipid profile [10]. Hence, the data concluded that the level of blood cholesterol and the number of patients suffering from hypertension increases with increasing age.

\section{TG level test}

The level of TG in the serum of 240 patients was observed using kitbased method. It was observed that out of 240 patients the level of TG in 100 patients was either below or near the borderline, that is, $\leq 150 \mathrm{mg} / \mathrm{dL}$ but their BP (systolic and diastolic) was much higher, that is, $145 / 95$ than the normal range of $120 / 80$ (Fig. 3). Further, in rest of the 140 patients the level of TG increased drastically to the range of $150->200 \mathrm{mg} / \mathrm{dL}$ with an evident rise in $\mathrm{BP}$ in range of 160/110-195/120 (Fig. 3).

On the other hand, after assessing the data as per the age groups it was observed that in the age group of 20-40 years out of $80(100 \%)$ subjects $60 \%$ have level of TG $<150 \mathrm{mg} / \mathrm{dL}$ whereas $30 \%$ patients were residing in the range of $150-199 \mathrm{mg} / \mathrm{dL}$ and only $10 \%$ having high TG level $>200 \mathrm{mg} / \mathrm{dL}$

However, when the age group range of the patients increased to 4160 years, out of 80 subjects $55 \%$ showed level of TG $<150 \mathrm{mg} / \mathrm{dL}$, $35 \%$ patients were residing in the range of $150-199 \mathrm{mg} / \mathrm{dL}$, and $10 \%$ showed high TG level $>200 \mathrm{mg} / \mathrm{dL}$.

Further, in the age group of $61-80$ years out of 100 subjects only $10 \%$ patient have $\mathrm{TG}<150 \mathrm{mg} / \mathrm{dL}$ whereas $60 \%$ patients were in the range of 150-199 mg/dL and around 30\% having high TG level $>200 \mathrm{mg} / \mathrm{dL}$ (Fig. 4).

Hence, the data conclude that in the age group of 20-40, 41-60, and 61-80-years overall percentage of patients having level of TG higher than $150 \mathrm{mg} / \mathrm{dL}$ increased to $40 \%, 45 \%$, and $90 \%$, respectively. Hence, Figs. 3 and 4 shows that with increase in age of the patients, the number of patients suffering from hypertension increased due to increase in their TG and systolic/diastolic BP levels.

In young adulthood, men tend to have higher triglyceride levels than women due to huge differences in their energy requirements and

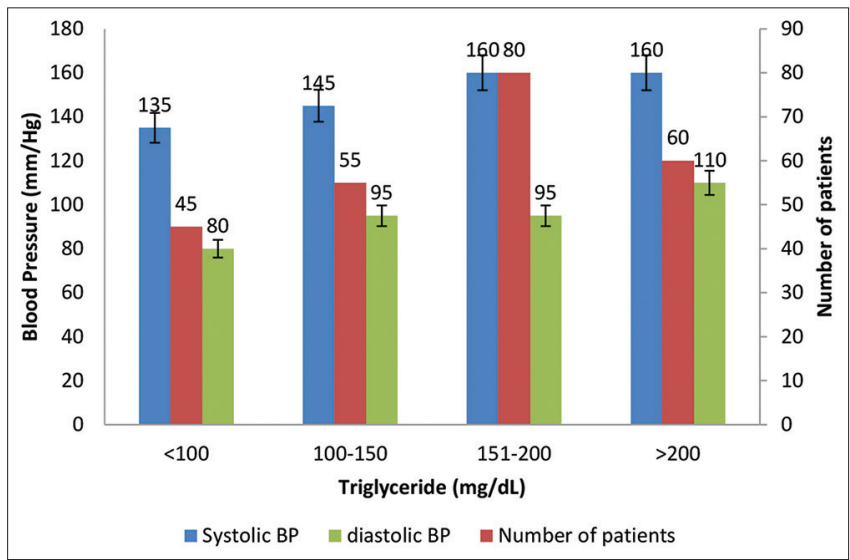

Fig. 3: Describing the relationship between levels of serum triglyceride (mg/dL) and systolic/diastolic blood pressure (mmHg) of 240 patients 
food habits [12]. This study also showed that in the lower age group of $20-40$ years out of $10 \%$ patients with TG $>200 \mathrm{mg} / \mathrm{dL}, 90 \%$ were males, and $10 \%$ were females. However, in $40-60$ years of age out of $10 \%$ patients with high TG levels of $>200 \mathrm{mg} / \mathrm{dL} 60 \%$ were males $40 \%$ were females indicating that level of TG started increasing in females as well after 40 years (Fig. 4). This might be due the loss of estrogen with menopause which is associated with an increase in abdominal adiposity as triglyceride levels increases during the menopausal transition [11]. A longitudinal study of the menopausal transition reported an increase of $16 \%$ in triglyceride values [13]. Thus, women with age higher than 40 years show higher levels of TG than females of younger age [12]. This study also indicated as the age increased above 60 years percentage of patients with level of TG> $200 \mathrm{mg} / \mathrm{dL}$ increased from $10 \%$ to $30 \%$ and among these numbers of affected female increased as compared to males.

\section{Determination of LDL levels in blood}

The blood samples of 240 patients of different age groups were collected and tested for their levels of LDL using procedure as described above. The level of LDL, along with the other factors such as TG, sodium and cholesterol, is also considered as the one of the major factors contributes to high BP in patient. LDL is considered as bad cholesterol as on oxidation it is responsible for atherosclerosis.

Fig. 5 describes that highest number (152) of patients were observed with LDL level in the range of $100-150 \mathrm{mg} / \mathrm{dL}$ which is in the normal to borderline range. In higher range of LDL levels from 151 to $>200 \mathrm{mg} / \mathrm{dL}$ although the number of patients was comparatively less

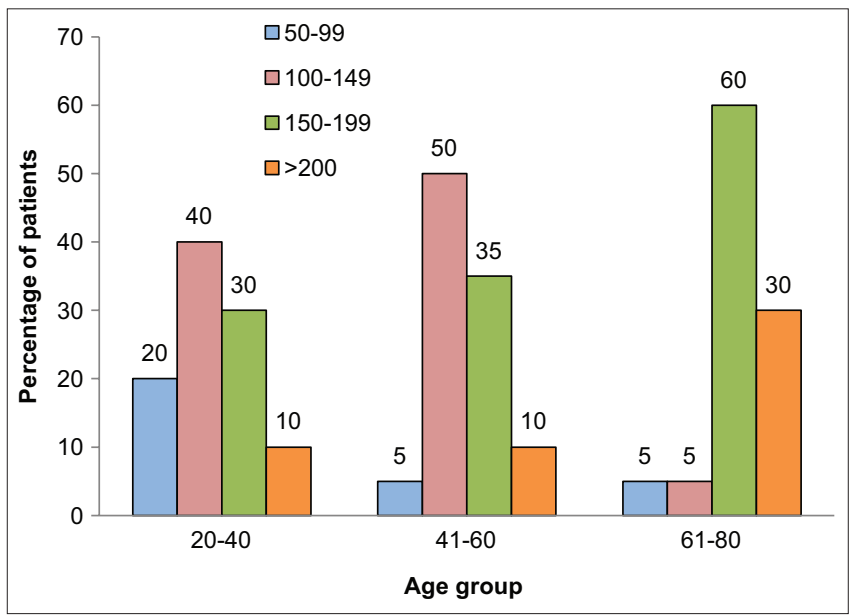

Fig. 4: Describing the levels of serum triglyceride $(\mathrm{mg} / \mathrm{dL})$ in patients (\%) of different age groups

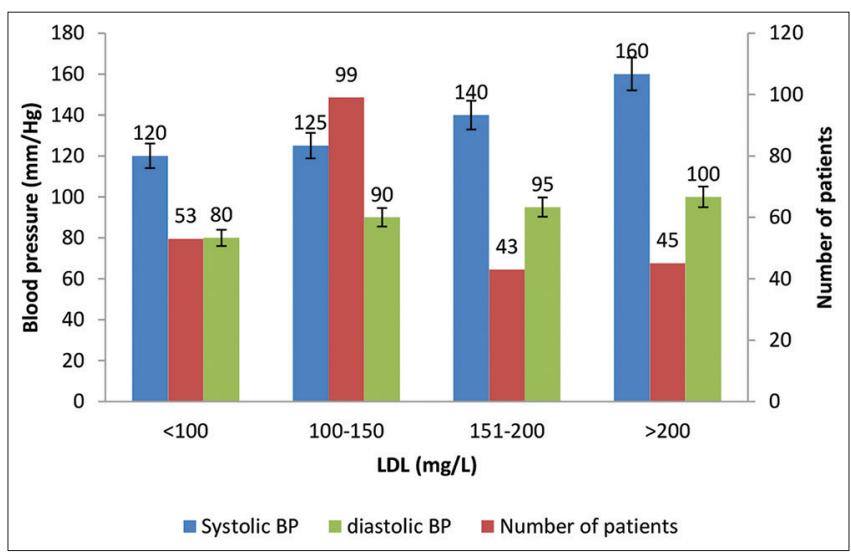

Fig. 5: Describing the relationship between levels of serum LDL $(\mathrm{mg} / \mathrm{dL})$ and systolic/diastolic blood pressure $(\mathrm{mmHg})$ of 240 patients
(88) but their BP (systolic and diastolic) was found to be increased up to $100 / 160 \mathrm{mmHg}$. This might be due to the fact that LDL is considered to carry cholesterol to the peripheral tissues where it can deposit and increase the BP and may leads to arteriosclerotic heart and peripheral vascular disease.

As per the age groups as shown in Fig. 6 out of 80 patients of $20-40$ years, only $10 \%$ patients were having level of LDL higher than $150 \mathrm{mg} / \mathrm{dL}$. Among these, $90 \%$ were males and $10 \%$ were females. Similarly, in the age group of 41-60 years, $40 \%$ patients were having level of LDL higher than $150 \mathrm{mg} / \mathrm{dL}$ among these $55 \%$ were males and $45 \%$ were females. In the age group of 61-80 years, the number of overall patients having level of LDL higher than $150 \mathrm{mg} / \mathrm{dL}$ increases to $60 \%$ among these $42 \%$ were males and $58 \%$ were females.

Hence, with increase in age group the percentage of patients having high level of LDL increases from $10 \%$ to $60 \%$ and it was also evident that females were more prone to increase in their LDL levels with increasing age. In case of young females, the level of estrogens increases HDL and on the same time improves hepatic clearance of LDL thus decrease LDL. However, in elderly females due to low postmenopausal estrogen level a decrease in HDL/LDL ratio can be observed which leads to higher risk of atherosclerosis-related disorders in females above 50 years [14].

The age-related studies also suggest that in plasma, levels of LDLcholesterol increase with aging and clearance of LDL decreases in both humans and rodents which becomes the key factor for the onset of atherosclerosis and CHD [14]. This is related to the decreased breakdown of cholesterol to bile acids and increased intestinal cholesterol absorption as observed in aging rodents [14]. In addition, it has been reported that in humans with increasing age from 20 to 60 years plasma LDL-cholesterol increases by about $40 \%$ [15]. The conditions get severed when along with LDL other factors such as high $\mathrm{TG}$, sodium level also contributes to high BP in patient.

\section{Recovery of patients after drug therapy/change in lifestyle}

Eleven (11) hypertensive patients were selected with high levels of cholesterol, TG and LDL in their serum and administrated orally to drugs such as Amlodipine, Atenolol, Telmisartan, Atorvastatin, and Ecosprin for 2 months as a monotherapy and/or in combination therapy as prescribed by their doctors. The younger patients belonging to age group of 20-40 years were having comparatively low cholesterol but high BP so administered to combination of Atenolol and Atorvastatin. Atenolol a beta blocker blocks the action of epinephrine and lowers the heart rate, BP, and strain on the heart. Atorvastatin raises the level of HDL in the blood. This efficiently controlled their BP and cholesterol levels within 60 days of treatment (Table 3).

Further, administration of Amlodipine along with Atenolol and Atorvastatin in combination majorly controlled the hypertension in

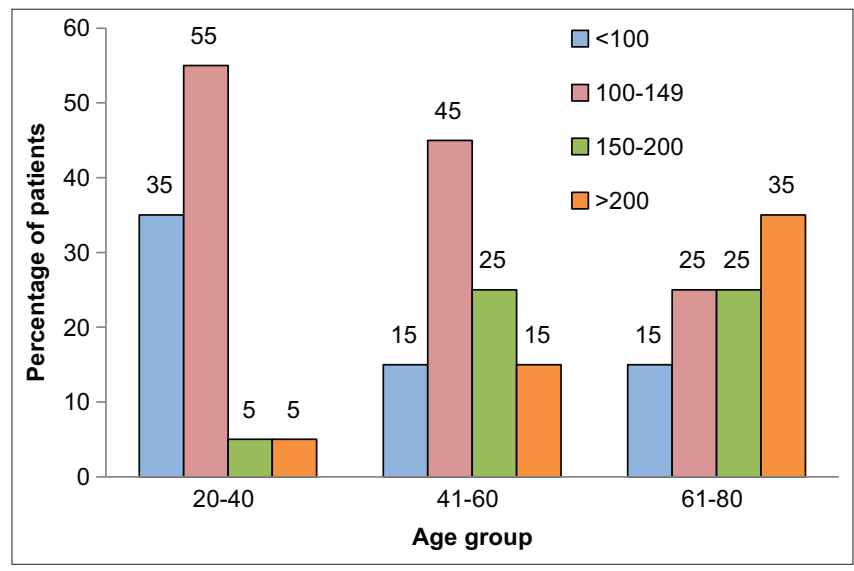

Fig. 6: Describing the levels of serum LDL (mg/dL) in patients (\%) of different age groups 
Table 3: Comparative parameters profile $\left(1^{\text {st }}\right.$ and $60^{\text {th }}$ day) of patients administered to drugs therapy and lifestyle changes

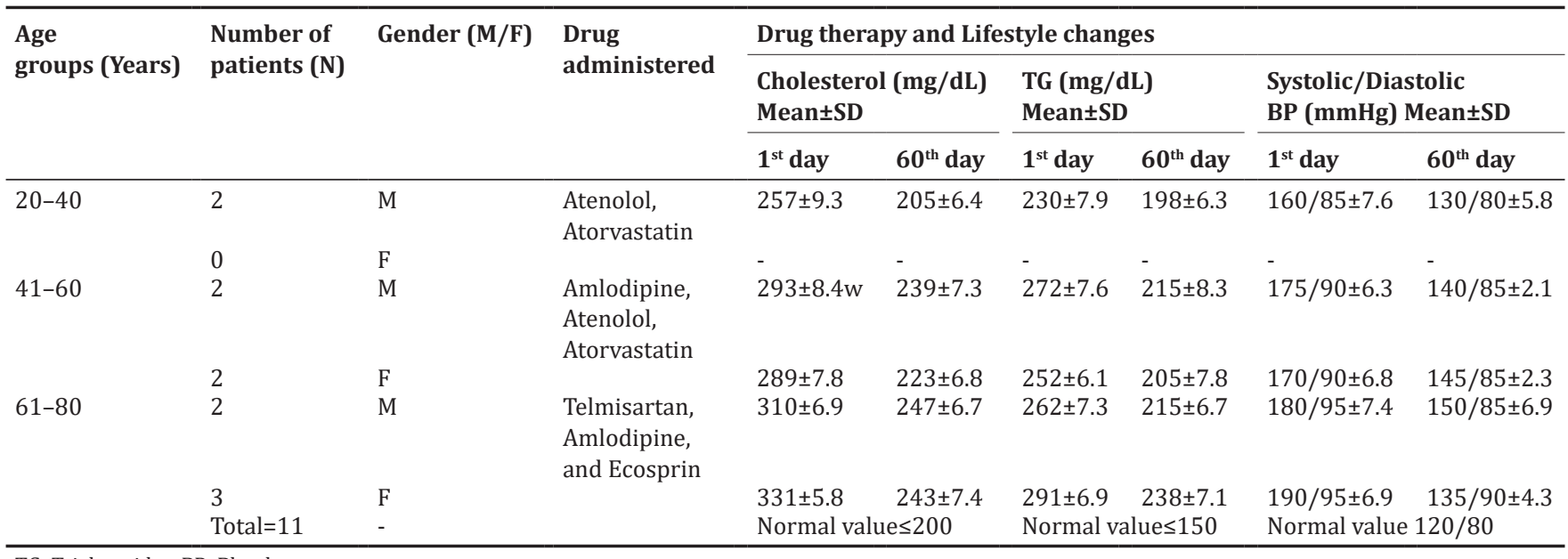

TG: Triglycerides, BP: Blood pressure

patients of higher age group of 41-60 years. Amlodipine acted as a calcium channel blocker and worked by relaxing blood vessels for smooth flow of blood. Thus, out of four patients (two males and two females), two males showed a drastic decrease in levels of cholesterol, TG, LDL, and BP after 60 days in comparison to their respective levels before taking medications/management (Table 3). In combination therapy, low doses were as effective as high doses of same drugs in monotherapies.

However, in even higher age group of 61-80 years a combination therapy of telmisartan, amlodipine, and Ecosprin has worked better than Atenolol and Atorvastatin as out of 5 patients (two males and three females), three females showed an effective control in BP and other recorded lipid parameters. In this case, Telmisartan an angiotensin receptor blocker, relaxed the blood vessels whereas and Ecosprin an antiplatelet drug was used to prevent clots in blood vessels and also relieved pain and inflammation which is commonly observed in aged patients [13]. In aged patients, monotherapies of these drugs have low efficiency as compared to their combination therapy to control hypertension and high dosage was required to efficiently normalize the BP. A study with 1461 patients revealed, that taking telmisartan $0,20,40$, and $80 \mathrm{mg}$ and amlodipine $0,2.5,5$, and $10 \mathrm{mg}$ for 60 days induces greater BP reductions with combination therapy than with respective monotherapies [13].

In addition, changes in their lifestyle and dietary habits were also planned such as incorporation of light exercise/brisk walking, inclusion of more fruits, vegetables, whole grains, fish, nuts, poultry, low-fat dairy products, oils with omega 3 fatty acids and, avoiding sugar-containing beverages, red meat, and sweets.

Hence, overall, seven out of 11 patients managed to control the BP and other parameters because they were strictly following the above prescribed diet and workout plans by their physicians (Table 3). It was observed that such patients after certain point of time were able to control their BP and lipid levels with comparatively low levels of drug dosages and came up with good health and physical parameters (data not shown). In the United States, National Harris interactive survey for hypertension, disclosed that only $50-60 \%$ patients remain involved in different kind of lifestyle change to control BP, whereas majority of patients rely only on medication to control hypertension [10]. Thus, a tight control of BP and lipid profile is required especially in female and aged persons to prevent later hypertension and heart related complications in life $[7,10]$.

\section{CONCLUSION}

The results of this study describe that patient with elevated levels of Cholesterol, LDL, and TG more likely to show hypertension with increasing age. The rise of these parameters was more significant in case of females above 40 years than that of males of same age group. This must be due to decreasing level of estrogen in postmenopausal women which is further aggravated by aging, lack of workout, and imbalanced diet. Hence, the study suggests that females should be more careful in monitoring their BP and lipid profile after 40 years.

Second, the study also included the role of drug intervention and change in lifestyle/dietary habits to control hypertension and related cardiovascular diseases in selected hypertensive patients. It was observed that, monotherapies of the selected drugs have low efficiency as compared to the combination drug therapy to control hypertension. In combination therapy, low doses were found as effective as high doses of same drugs in monotherapies. More than $60 \%$ of these patients showed a significant improvement in their health, BP, and lipid profile.

Third, the data indicated that different types of drug and lifestyle changes are required for patients of different age group as same schedule may not be effective to control the hypertension and lipid profile in all age groups.

Finally, it was observed that those patients who rely only on drug therapies were less likely to control their high BP and lipid parameters. However, those who changed their food habits and included workout regime as prescribed in their lifestyle showed a better improvement in their BP and lipid levels.

\section{CONFLICTS OF INTEREST/AUTHOR'S CONTRIBUTIONS}

There is no conflict of interest among authors. All authors have participated in (a) conception and design, or analysis and interpretation of the data; (b) drafting the article or revising it critically for important intellectual content; and (c) approval of the final version.

\section{AUTHOR'S FUNDING}

We acknowledge the financial support and the ambient laboratory environment provided by charitable organization of Khalsa College of Pharmacy and Technology, Amritsar, India for this study.

This manuscript has not been submitted to, nor is under review at any other journal or other publishing venue.

\section{REFERENCES}

1. Lopez AD, Mathers CD, Ezzati M, Jamison DT, Murray CJ. Global and regional burden of disease and risk factors, 2001: Systematic analysis of population health data. Lancet 2006;367:1747-57.

2. Mackay J, Mensah GA. The Atlas of Heart Disease and Stroke. Geneva: 
World Health Organization; 2004

3. Hypertension Study Group. Prevalence, awareness, treatment and control of hypertension among the elderly in Bangladesh and India: A multicentre study. Bull World Health Organ 2001;79:490.

4. Littlejohn TW, Majul CR, Olvera R, Seeber M, Kobe M, Guthrie R, et al. Results of treatment with telmisartan-amlodipine in hypertensive patients. J Clin Hypertens 2009;11:207-13.

5. Hansson L, Zanchetti A, Carruthers SG, Dahlöf B, Elmfeldt D, Julius S, et al. Effects of intensive blood-pressure lowering and low-dose aspirin in patients with hypertension: Principal results of the hypertension optimal treatment (HOT) randomized trial. Lancet 1998;351:1755-62.

6. Eapen DJ, Kalra, GL, Rifai L, Eapen CA, Merchant N, Khan BV. Raising HDL cholesterol in women. Int J Womens Health Wellness 2009;1:181.

7. Sun LP, Seemann J, Goldstein JL, Brown MS. Sterol-regulated transport of SREBPs from endoplasmic reticulum to Golgi: Insig renders sorting signal in Scap inaccessible to COPII proteins. Proc Natl Acad Sci 2007; $104: 6519-26$

8. Lim SS, Vos T, Flaxman AD, Danaei G, Shibuya K, Adair-Rohani H. A comparative risk assessment of burden of disease and injury attributable to 67 risk factors and risk factor clusters in 21 regions, 1990-2010: A systematic analysis for the global burden of disease study 2010. Lancet 2012;380:2224-60.

9. Poehlman ET, Toth MJ, Ades PA, Rosen CJ. Menopause-associated changes in plasma lipids, insulin-like growth factor I and blood pressure: A longitudinal study. Eur J Clin Invest 1997;4:322-6.

10. Moser M, Franklin SS. Hypertension management: Results of a new national survey for the hypertension education foundation: Harris interactive. J Clin Hypertens 2007;9:316-23.

11. Carr MC. The emergence of the metabolic syndrome with menopause. J Clin Endo Crinol Metab 2003;88:2404-11.

12. Corpas E, Harman SM, Blackman MR. Human growth hormone and human aging. Endocr Rev 1993;14:20-39.

13. Sowers JR. Hypertension in the elderly. Am J Med 1987;82:1-8

14. Elahi D, Muller DC, Egan J.M, Andres R, Veldhuis J, Meneilly GS. Glucose Tolerance, Glucose Utilization and Insulin Secretion in Ageing, Novartis Foundation Symposia. Chichester, New York: John Wiley; 2002. p. 222-46.

15. Parini P, Angelin B, Rudling M, Cholesterol and lipoprotein metabolism in aging: Reversal of hypercholesterolemia by growth hormone treatment in old rats. Arterioscler Thromb Vasc Biol 1999;19:832-9. 